PENGARUH LEADERSHIP TRANSFORMASIONAL, ORGANIZATIONAL CITIZENSHIP BEHAVIOR DAN KOMITMEN ORGANISASIONAL TERHADAP KINERJA KARYAWAN PT. BANK RAKYAT INDONESIA(PERSERO)TBK, KANTOR CABANG TULANG BAWANG

\author{
Tiar Mirnasari ${ }^{1}$, Nuzleha ${ }^{2}$, Barron Nugroho Al Amin ${ }^{3}$ \\ Fakultas Ekonomi, Universitas Sang Bumi Ruwa Jurai \\ tiarmirnasari2020@gmail.com,nuzlehahadjar1970@gmail.com,barron.nugroho.alamin@gmail.com
}

\begin{abstract}
Abstrak
Penelitian ini merupakan studi yang bertujuan untuk mengetahui pengaruh leadership transformasional, organizational citizenship behavior dan komitmen organisasional terhadap kinerja. Populasi dalam penelitian ini adalah seluruh karyawan tetap dari perusahaan PT.Bank Rakyat Indonesia (Persero)Tbk Kantor Cabang Tulang Bawang yang berjumlah 237 karyawan, besarnya sampel yang dapat mewakili populasi untuk diteliti adalah sebanyak 149 responden. Metode analisis yang digunakan adalah regresi berganda,dengan uji t sebagai uji hipotesis penelitian. Berdasarkan hasil penelitian yang telah dilakukan, dapat diketahui secara parsial hanya variabel komitmen organisasional yang tidak berpengaruh terhadap kinerja karyawan, sedangkan variabel leadership transformasional, dan organizational citizenship mempengaruhi secara positif dan signifikan terhadap kinerja karyawan, hasil penelitian juga membuktikan terdapat pengaruh positif leadership transformasional, organizational citizenship behavior dan komitmen organisasional secara bersama-sama terhadap kinerja karyawan
\end{abstract}

Kata Kunci : leadership transformasional, organizational citizenship behavior, komitmen organisasional, kinerja karyawan.

\begin{abstract}
This research is a study to eploring relation between transformational leadership, organizational citizenship behavior and organizational citizenship behavior and organizational commitment on employee performance both partial and simultaneous. Population on this research are all employees of PT. Bank Rakyat Indonesia (Persero), Tbk .Branch Office Tulang Bawang which consist of 237 employees. Amount of sample to represent this population are 149 respondents. Analysis method which used is primary data with questionnaire as the research instrument. Based on research have done, partial result of independent variabel which are transformational leadership, organizational citizenship behavior and organizational commitment positive and significantly affect to employee performance. This result also proved that there are positive and significant effect simultaneously on variabels of transformational leadership, organizational citizenship behavior and organizational commitment on employee commitment.
\end{abstract}

Keywords : transformational leadership, organizational citizenship behavior and organizational commitment, employee performance.

\title{
PENDAHULUAN
}

PT. Bank Rakyat Indonesia (Persero) Tbk. berdirisejak 16 Desember 1895 di Purwokerto, Jawa Tengah. Pemegang sahammayoritas PT. Bank Rakyat Indonesia (Persero) Tbk. adalahPemerintahRepublik Indonesia denganjumlahkepemilikansahammencapai 56,75\%, 
Seminar Nasional Penelitian dan Pengabdian kepada Masyarakat Universitas Sang Bumi Ruwa Jurai Tahun 2020

sementarasisanyasebesar 43,25\% dimiliki oleh pemegangsahampublik (Annual ReportPT. Bank Rakyat Indonesia (Persero) Tbk., 2019).

Sebagai bank komersialtertua, saatini PT. Bank Rakyat Indonesia (Persero) Tbk. memiliki 19 kantor wilayah, 1 kantor inspeks ipusat, 19 kantorinspeksi wilayah, 462 kantorcabangdomestik, 1 kantorcabangkhusus, 603 kantorcabangpembantu, 983 kantor kas, 5.360 kantor unit, 3.178 teras dan 1 teras kapal. Dari ke-19 kantor wilayah yang tersebar di seluruh wilayah Indonesia, kantor wilayah yang paling barudidirikanadalah Kantor Wilayah Bandar Lampung yang didirikan pada tahun 2018 denganmembawahiduaprovinsiyaitu Lampung dan Bengkulu. Unit kerja PT. Bank Rakyat Indonesia (Persero) Tbk yang berada di bawahsupervisi PT. Bank Rakyat Indonesia (Persero) Tbk.Kantor Wilayah Bandar Lampung terdiriatas 10 kantorcabang, 14 kantorcabangpembantu, 9 kantor kas, 165 kantor BRI unit, 53 teras BRI, 14 teras $\underline{B R I}$ keliling, 433 ATM, dan 1.660 EDC yang tersebar di wilayah Provinsi Lampung dan Bengkulu. PT. Bank Rakyat Indonesia (Persero) Tbk. diharapkanmemberikandukunganpengalaman dan kemampuan yang matang di dalammemberikanlayananperbankan, terutama pada produktabungan, produktabungan yang paling diandalkan dan memilikijumlahnasabahterbesaradalahBritAma. Dari data yang diperoleh,berikutadalahtabel yang menunjukanperkembangan Tabungan BritAma Kantor wilayah BRI Lampung:

Tabel 1

Perkembangan Tabungan BritAmaTahun 2018 dan 2019

\begin{tabular}{|c|c|c|c|c|c|c|c|}
\hline \multirow[b]{2}{*}{ No } & \multirow[b]{2}{*}{ Kantor Cabang } & \multicolumn{2}{|c|}{ Tahun 2014} & \multicolumn{2}{|c|}{ Tahun 2015} & \multicolumn{2}{|c|}{$\begin{array}{c}\text { RealisasiTerhadap } 31 \\
\text { Des } 2015\end{array}$} \\
\hline & & Rek & Jumlah (Jt) & Rek & Jumlah (Jt) & Rek & Jumlah (Jt) \\
\hline 1 & TulangBawang & 17.656 & 143.872 & 19.269 & 150.281 & $8,37 \%$ & $4,26 \%$ \\
\hline 2 & TanjungKarang & 61.742 & 483.911 & 75.310 & 569.460 & $18,02 \%$ & $15,02 \%$ \\
\hline 3 & Kalianda & 12.542 & 64.158 & 13.914 & 68.620 & $9,86 \%$ & $6,50 \%$ \\
\hline 4 & Metro & 38.750 & 228.809 & 43.063 & 266.801 & $10,02 \%$ & $14,24 \%$ \\
\hline 5 & TelukBetung & 26.889 & 137.999 & 34.029 & 159.815 & $20,98 \%$ & $13,65 \%$ \\
\hline 6 & Kotabumi & 26.618 & 151.369 & 33.127 & 185.672 & $19,65 \%$ & $18,48 \%$ \\
\hline 7 & Liwa & 6.675 & 52.949 & 11.592 & 74.392 & $42,42 \%$ & $28,82 \%$ \\
\hline 8 & Bandar Jaya & 19.913 & 118.765 & 26.822 & 145.927 & $25,76 \%$ & $18,61 \%$ \\
\hline 9 & TulangBawang & 23.559 & 139.997 & 28.095 & 166.222 & $16,15 \%$ & $15,78 \%$ \\
\hline 10 & Argamakmur & 15.306 & 95.192 & 21.441 & 112.440 & $28,61 \%$ & $15,34 \%$ \\
\hline
\end{tabular}

Sumber: PT Bank Rakyat Indonesia Tbk, 2016

Tabel 1 menjelaskan bagaimana perkembangan perkembangan Tabungan BritAma Kantor wilayah BRI Lampung, data ini menggambarkan pencapaian terbesar dimiliki oleh Kantor Cabang Liwa dengan peningkatan jumlah nasabah atau rekening sebesar 42,42\% dan jumlah dana tabungan meningka tsebesar 28,82\%, dan terkecil yaitu BRI Cabang Kalianda dengan realisasi pada tahun 2015 sebesar 13.914 nasabah BritAma, sedangkan Cabang TulangBawangmemilikipersentaseperubahannasabah yang lebih kecil disbanding kantor cabang lainnya di Lampung dengan persentase jumlah nasabahs ebesar 8,37\%. 
Selain jumlah perkembangan produk simpanan, kinerja karyawan juga dapat dilihat perkembangan non performing loan (NPL). Non performing loan atau biasa disebut NPL ini merupakan kredit bermasalah yang merupakan salah satu kunci untuk menilai kualitas kinerja bank. Non performing loan (NPL) adalah salah satu indicator kunci untuk menilai kinerja fungsi bank, karena NPL yang tinggi adalah indicator gagalnya bank dalam mengelola bisnis antara lain timbul masalah likuiditas (ketidakmampuan membayar pihak ketiga), rentabilitas (utang tidak bias ditagih), solvabilitas (modal berkurang). Sedangkan laba yang merosot adalah salah satu imbasnya Karena praktis bank kehilangan sumber pendapatan di samping harus menyisihkan pencadangan sesuai kolektibilitas kredit. Kehati-hatian yang dilakukan manajemen dalam memberikan kredit dapat mengurangi risiko kredit macet, oleh karena itu diperlukan manajemen yang baik agar memiliki kinerja NPL yang baik. Berikut tabel yang menunjukan perubahan realisasi NPL dari tahun 2018 terhadap tahun 2019 Kantor Cabang BRI di Provinsi Lampung:

Tabel 2.Perubahan Realisasi NPL Kantor Cabang BRI Provinsi Lampung Tahun 2018 terhadap Tahun 2019

\begin{tabular}{|c|c|c|c|c|c|c|c|c|}
\hline \multirow[b]{2}{*}{ No } & \multirow[b]{2}{*}{ Kantor Cabang } & \multicolumn{2}{|c|}{ Tahun 2018} & \multicolumn{2}{|c|}{ Tahun 2019} & \multicolumn{2}{|c|}{ Perubahan 2018-2019 } & \multirow{2}{*}{$\begin{array}{l}\text { Sumber: } \\
\text { PT Bank }\end{array}$} \\
\hline & & Deb & Jumlah (Jt) & Deb & Jumlah $(\mathrm{Jt})$ & Deb & Jumlah (Jt) & \\
\hline 1 & TulangBawang & 102 & 7.135 & 82 & 7.258 & 20 & -122 & \\
\hline 2 & TanjungKarang & 400 & 25.658 & 315 & 12.486 & 85 & 13172 & Rakyat \\
\hline 3 & Kalianda & 105 & 4.181 & 124 & 8.180 & -19 & -3999 & Indonesia \\
\hline 4 & Metro & 658 & 18.519 & 349 & 17.234 & 309 & 1284 & тиотеsia \\
\hline 5 & TelukBetung & 499 & 20.435 & 210 & 20.735 & 289 & -300 & Tbk, 2019 \\
\hline 6 & Kotabumi & 874 & 21.866 & 557 & 14.913 & 317 & 6953 & \\
\hline 7 & Liwa & 80 & 3.815 & 104 & 2.734 & -24 & 1081 & Ter \\
\hline 8 & Bandar Jaya & 393 & 8.936 & 360 & 8.869 & 33 & 68 & lihat \\
\hline 9 & TulangBawang & 607 & 14.956 & 597 & 19.286 & 10 & -4329 & pada \\
\hline & Argamakmur & 368 & 8561 & 280 & 6732 & 88 & 1829 & Tabel \\
\hline
\end{tabular}

realisasi NPL dari tahun 2018 terhadap 2019 Kantor Cabang BRI di Provinsi Lampung, dengan perubahan terbesar dimiliki oleh kantor cabang Tulang Bawang dengan Rp.-4.329 juta tetapi jumlah debitur yang menunggak bertambah 10 debitur, sedangkan yang terbaik dimiliki oleh kantor cabang Kotabumi dengan perubahan debitur yang menunggak berkurang menjadi 317 debitur dan dana yang menunggak berkurang menjadi Rp.6.953 Juta, selain itu kantor cabang TulangBawang juga memiliki pencapaian terhadap target yang terkecil dibandingkan dengan kantor cabang lain, hal ini tidak terlepas dari kinerja karyawan didalamnya karena karyawan merupakan asset utama dalam perusahaan dan mempunyai peran yang strategis di dalam perusahaan yaitu sebagai pengendali aktivitas perusahaan yang dituangkan dalam setiap tugas dan pekerjaan, keseluruhan tersebut tidak lepas dari peran efektif seorang pemimpin.

BRI Kantor Cabang Tulang Bawang merupakan kantor cabang yang membawahi 20 kantor unit yang keseluruhannya tersebar di seluruh area Tulang Bawang. Literatur organisasi dan manajemen menggambarkan leadership karyawan sebagai bagian integral dari organisasi. Kualitas dari pemimpin seringkali dianggap sebagai factor terpenting yang menentukan keberhasilan atau kegagalan organisasi. Agar menjadi pemimpin yang efektif, seorang pimpinan 
cabang harus dapat mempengaruhi seluruh karyawan yang dipimpinnya melalui cara-cara yang positif untuk mencapai tujuan organisasi, dalam hal ini pimpinan kantor unit diperlukan, karena menurut Dunn dan Sims (2012) mengemukakan bahwa leadership adalah aktivitas mempengaruhi orang-orang agar mereka suka berusaha mencapai tujuan-tujuan kelompok. Menurut Robbins dan Judge (2008) bahwa gaya leadership merupakan suatu strategi atau kemampuan dalam mempengaruhi suatu kelompok kearah tercapainya tujuan.

Ismail et al. (2011) menyatakan bahwa pada era persaingan global, banyak organisasi menggeser paradigm gaya leadership mereka dari leadership transaksional ke leadership transformasional sebagai cara untuk mencapai strategi dan tujuan. Gaya leadership transformasional sesuai dengan lingkungan organisasi yang dinamis (Ismail et al., 2011). Leadership transformasional dianggap efektif dalam situasi atau budaya dan organisasi apa pun (Yukl, 2010). Khuntia dan Suar (2004) menegaskan bahwa pemimpin yang menerapkan leadership transformasional memberikan pengaruhnya kepada para pengikut dengan melibatkan pengikutnya berpartisipasi dalam penentuan tujuan, pemecahan masalah, pengambilan keputusan, dan memberikan umpan balik melalui pelatihan, pengarahan, konsultasi, bimbingan, dan pemantauan atas tugas yang diberikan. Pemimpinan transformasional adalah pemimpin yang mendorong para pengikutnya untuk merubah motif, kepercayaaan, nilai, dan kemampuan sehingga minat dan tujuan pribadi dari para pengikut dapat selaras dengan visi dan tujuan organisasi (Goodwin et al., 2001).

Sumber daya manusia mempunyai peran yang sangat penting disamping sumber-sumber daya lain yang dimiliki organisasi, salah satu factor tersebut adalah Organizational citizenship behavior (OCB). Organ et al, (2006) mendefinisikanOCB sebagaiperilaku individual yang bersifat bebas, yang tidak secara langsung dan eksplisit mendapat penghargaan dari system imbalan formal, dan yang secara keseluruhan meningkatkan efisiensi dan efektifitas fungsifungsi organisasi. Bersifat bebas dan sukarela, karena perilaku tersebut tidak diharuskan oleh persyaratan peran atau deskripsi jabatan yang secara jelas dituntut berdasarkan kontrak dengan organisasi, melainkan sebagai pilihan personal. OCB sangat penting artinya untuk menunjang keefektifan fungsi-fungsi organisasi, terutama dalam jangka panjang. Menurut Podsakoff et al. (2000), OCB mempengaruhi keefektifan organisasi. Individu yang member kontribusi pada keefektifan organisasi dengan melakukanhal di luar tugas atau peran utama mereka adalah aset bagi organisasi. Berdasarkan observasi awal diperolehin formasi telah terjadinya penurunan disiplin karyawan. Hal ini terlihatdari data keterlambatan karyawan Bank BRI Cabang TulangBawang, seperti terlihat dalam tabel berikut:

Tabel 3

Total AbsensiKaryawan Bank BRI Cabang TulangBawangTahun 2019

\begin{tabular}{|c|c|c|c|c|c|c|}
\hline & & & Jumlah & Jumlah & Tingk & Tingkat \\
\hline & & Jumlah hari & & absensi & & \\
\hline \multirow[t]{3}{*}{ Tahun } & Bulan & & Karyawan & & absen & Tolerir \\
\hline & & kerja (hari) & & karyawan & & \\
\hline & & & (orang) & (arang) & $(\%)$ & Absensi \\
\hline 2019 & Januari & 22 & 237 & 54 & $1,04 \%$ & $1,00 \%$ \\
\hline 2019 & Februari & 21 & 237 & 64 & $1,29 \%$ & $1,00 \%$ \\
\hline 2019 & Maret & 23 & 237 & 48 & $0,88 \%$ & $1,00 \%$ \\
\hline
\end{tabular}


Seminar Nasional Penelitian dan Pengabdian kepada Masyarakat Universitas Sang Bumi Ruwa Jurai Tahun 2020

\begin{tabular}{ccccccc}
\hline $\mathbf{2 0 1 9}$ & April & 22 & 237 & 40 & $0,77 \%$ & $1,00 \%$ \\
\hline \hline $\mathbf{2 0 1 9}$ & Mei & 23 & 237 & 50 & $0,92 \%$ & $1,00 \%$ \\
\hline \hline $\mathbf{2 0 1 9}$ & Juni & 21 & 237 & 42 & $0,84 \%$ & $1,00 \%$ \\
\hline \hline $\mathbf{2 0 1 9}$ & Juli & 20 & 237 & 46 & $0,97 \%$ & $1,00 \%$ \\
\hline \hline $\mathbf{2 0 1 9}$ & Agustus & 21 & 237 & 44 & $0,88 \%$ & $1,00 \%$ \\
\hline \hline $\mathbf{2 0 1 9}$ & September & 22 & 237 & 66 & $1,27 \%$ & $1,00 \%$ \\
\hline \hline $\mathbf{2 0 1 9}$ & Oktober & 22 & 237 & 54 & $1,04 \%$ & $1,00 \%$ \\
\hline \hline $\mathbf{2 0 1 9}$ & November & 21 & 237 & 60 & $1,21 \%$ & $1,00 \%$ \\
\hline \hline Ra19 & Desember & 22 & 237 & 60 & $1,15 \%$ & $1,00 \%$ \\
\hline \hline
\end{tabular}

Sumber: PT Bank Rakyat Indonesia Cabang Tulang Bawang, 2019

Tabel di atas memperlihatkan tingkat absensi karyawan selama tahun 2019 mempunyai rata-rata sebesar $1,02 \%$ lebih besar dari tingkat tolerir absensi yang ditetapkan BRI pusat yaitu sebesar 1\%, permasalahan ini harus mendapatkanperhatian yang sungguh-sungguh dari manajemen BRI Cabang Tulang Bawang, untuk mengatasi persoalan yang terungkap di atas, yang mana seorang karyawan dihadapkan oleh sejumlah tugas dan tanggung jawab yang besar serta tuntutan akan peran profesinya, dan di lain pihak adanya keterbatasan yang dimiliki oleh karyawan itu sendiri maupun keterbatasan akan apa yang diharapkan untuk diperoleh dari pekerjaannya, sangat dibutuhkan perilaku ekstra peran dari para karyawan yang dikenal sebagai OCB. Setiap orang yang bekerja di suatu perusahaan atau organisasi, harus memiliki komitmen dalam bekerja karena apabila suatu perusahaan karyawannya tidak mempunyai suatu komitmen dalam bekerja, maka tujuan dari perusahaan atau organisasi tersebut tidak akan tercapai.

Komitmen organisasional merupakan sikap yang menunjukkan loyalitas karyawan dan merupakan proses berkelanjutan bagaimana seorang anggota organisasi mengekspresikan perhatian mereka kepada kesuksesan dan kebaikan organisasinya. Komitmen organisasional (organizational commitment), didefinisikan sebagai suatu keadaan seseorang karyawan memihak organisasi tertentu serta tujuan-tujuan dan keinginannya untuk mempertahankan keanggotaan dalam organisasi tersebut. Jadi, keterlibatan pekerjaan yang tinggi berarti memihak pada pekerjaan tertentu seseorang individu, sementara komitmen organisasional yang tinggi berarti memihak dan organisasi yang merekrutin divide tersebut (Robbins, 2008).

Komitmen organisasional didefinisikan oleh Dunn dan Sims (2012) sebagai perasaan yang kuat dan erat dari seseorang terhadap tujuan dan nilai suatu organisasi dalam hubungannya dengan peran mereka terhadap upaya pencapaian tujuan dan nilai-nilai tersebut. Berikut adalah tabel yang memperlihatkan program kerja yang berhubungan dengan kinerja karyawan pada BRI Cabang Tulang Bawang dan pelaksanaanya di tahun 2019.

\section{Tabel 4}

Program Kerja BRI Cabang Tulang Bawang, 2019

\begin{tabular}{|c|c|c|c|}
\hline No & RencanaKerja & Target & Realisasi \\
\hline 1. & $\begin{array}{l}\text { Penagihan piutang nasabah } \\
\text { yang mengalami } \\
\text { Penunggakan }\end{array}$ & $\begin{array}{l}100 \% \text { tunggakan } \\
\text { terpenuhi. }\end{array}$ & Hanya $60 \%$ terpenuhi \\
\hline 2. & $\begin{array}{l}\text { Menambah jumlah nasabah } \\
\text { Baru }\end{array}$ & 15.000 nasabah baru & Hanya terpenuhi $55 \%$ \\
\hline
\end{tabular}


Sumber: PT Bank Rakyat Indonesia Cabang Tulang Bawang, 2019

Dari Tabel 4 dapat terlihat bahwa dari dua rencana kerja yang ada pada tahun 2019 tidak adanya realisasi yang dicapai oleh perusahaan, table tersebut memperlihatkan bahwa kinerja karyawan pada BRI Cabang Tulang Bawang belum terlaksana dengan baik. Hal ini menunjukanbahwa BRI Cabang Tulang Bawang memerlukan good management artinya harus mengembangkan Sumber Daya Manusia sebagai good manager dan organisasi yang baik, maka untuk meningkatkan kinerja perusahaan sangat dipengaruhi oleh kemampuan seorang pemimpin dalam menggerakkan bawahannya untuk bekerjasama dalam melaksanakan tugasnya secara efektif dan efisien.

Berdasarkan latar belakang yang dipaparkan, sehingga peneliti mengadakan penelitian di PT Bank Rakyat Indonesia (Persero) Kantor Cabang Tulang Bawang Provinsi Lampung dengan judul "Pengaruh Leadership Transformasional, Organizational Citizenship Behavior Dan Komitmen Organisasional Terhadap Kinerja Karyawan Bank Rakyat Indonesia Persero Kantor Cabang Tulang Bawang”.

\section{METODE PENELITIAN}

Metode analisis yang digunakan adalah regresi berganda,dengan uji t sebagai uji hipotesis penelitian. Penelitian ini menggunakan data primer yang berasal dari karyawan tetap dari perusahaan PT. Bank Rakyat Indonesia (Persero) Kantor Cabang Tulang Bawang sebagai subjek penelitian. Variabel penelitian ini terdiri atas 2 jenis, yaitu variabel bebas (independent variabel) dan variabel terikat (dependent variabel). Variabel bebas (independent variabel) adalah leadership transformasional, organizational citizenship behavior dan komitmen organisasional, sedangkan yang menjadi variabel terikat (dependent variabel) adalah kinerja karyawan.

Populasi dalam penelitian ini adalah seluruh karyawan tetap dari perusahaan PT Bank Rakyat Indonesia (Persero) Kantor Cabang Tulang Bawang yang berjumlah 237 karyawan. Sampel merupakan sebagian dari populasi yang diteliti.

Sampel dalam penelitian ini diambil dengan menggunakan rumus Slovin dalam Umar (2003) sebagai berikut:

$\eta=\frac{\mathrm{N}}{1+\mathrm{Ne}^{2}}$

Keterangan:

$\mathrm{n}=$ Jumlah sampel

$\mathrm{N}=$ Jumlah populasi

$\mathrm{e}=$ Batas kesalahan maksimal yang ditolerir dalam sampel $(5 \%)$

Dimana diketahui :

$$
\begin{aligned}
& n=\frac{237}{1+237(0,05)^{2}} \\
& =\frac{237}{1+0,5925}=148,82 \approx 149
\end{aligned}
$$

Jadi berdasarkan penghitungan diatas, jumlah sampel sebesar 149 responden dari 237 jumlah populasi. Teknik pengambilan sampel yang digunakan adalah Proporsional random sampling. Teknik Proportional Random Sampling merupakan teknik pengambilan sampel 
Seminar Nasional Penelitian dan Pengabdian kepada Masyarakat Universitas Sang Bumi Ruwa Jurai Tahun 2020

dengan anggota populasi yang dilakukan secara proportional. Sampel yang diperoleh adalah sebagai berikut:

Tabel 5. Teknik PengambilanSampel

\begin{tabular}{llcclcc}
\hline No & Unit & \multicolumn{1}{c}{ KaryawanSampel } & No & Unit & Karya & \\
wan & Sampel \\
\hline 1 & KC Tulang Bawang 2 & 16 & 10 & 11 Kas Tulang Bawang 2 & 10 & 6 \\
2 & KCP Rawajitu & 12 & 8 & 12 Kas Mesuji & 9 & 6 \\
3 & Kas RSUD Menggala & 12 & 8 & 13 Simpang Penawar & 9 & 6 \\
4 & Bogatama & 9 & 6 & 14 Kas Tulang Bawang 3 & 9 & 6 \\
5 & Brabasan & 15 & 9 & 15 Kas RSUD Mesuji & 11 & 7 \\
6 & Tulang Bawang 1 & 16 & 10 & 16 Kas Mesuji Timur & 12 & 8 \\
7 & Menggala C & 12 & 8 & 17 Kas Simpang Pematang & 14 & 9 \\
8 & Mesuji Timur & 10 & 6 & 18 Kas Menggala & 11 & 7 \\
9 & Rajawali & 11 & 7 & 19 Kas Rawajitu & 14 & 9 \\
10 & Simpang Pematang & 10 & 6 & 20 Kas Tulang Bawang 1 & 15 & 9 \\
\hline
\end{tabular}

Total Karyawan 237 dan JumlahSampel 149

\section{HASIL DAN PEMBAHASAN}

\section{Uji Hipotesis}

\section{Regresi Berganda}

Analisis regresi berganda meliputi berbagai perhitungan dan pengujian yaitu penentuan persamaan regresi, perhitungan koefisien determinasi, pengujian signifikansi variabel independen, dalam penelitian ini perhitungan regresi dilakukan untuk menguji hipotesis, berikut hasil perhitungan regresi model pertama:

Tabel 6.Coefficients

\begin{tabular}{|c|c|c|c|c|c|c|}
\hline & & \multicolumn{2}{|c|}{$\begin{array}{l}\text { Unstandardi } \\
\text { zed } \\
\text { Coefficien }\end{array}$} & \multirow{2}{*}{$\begin{array}{l}\text { Standardize } \\
\text { d } \\
\text { Coefficients } \\
\quad \mathrm{Be} \\
\text { ta }\end{array}$} & \multirow{3}{*}{$\begin{array}{l}\mathbf{t} \\
5,08\end{array}$} & \multirow{3}{*}{$\begin{array}{l}\text { Sig. } \\
\quad, 00\end{array}$} \\
\hline \multicolumn{2}{|c|}{ Model } & $\mathrm{B}$ & Std.Error & & & \\
\hline 1 & (Constant) & 2,133 & ,41 & & & \\
\hline & KT & ,202 & ,07 &, 22 & 2,54 & ,01 \\
\hline & OCB & ,205 & ,09 &, 17 & 2,12 & ,03 \\
\hline & KO & ,099 & ,05 & ,14 & 1,69 & ,09 \\
\hline
\end{tabular}

a.Dependent Variabel:KK

BerdasarkanTabel 6 dapat dibuat persamaan regresi linier berganda sebagai berikut :

$\mathrm{KK}=2,133+0,202 \mathrm{KT}+0,205 \mathrm{OCB}+0,099 \mathrm{KO}$ 
Nilai koefisien masing-masing variabel bebas bertanda positif, dan variabel terikat kinerja karyawan bertanda positif sebesar2,133 hal ini berarti apabila variabel bebas yaitu leadership transformasional, organizational citizenship behavior dan komitmen organisasional diasumsikan nol (0) maka kinerja karyawan PT.Bank Rakyat Indonesia (Persero), Tbk Kantor CabangTulangBawang akan sebesar 2,133.

\section{Uji Koefisen Determinasi $\left(\mathbf{R}^{2}\right)$}

Tabel 7.UjiKoefisenDeterminasi $\left(\mathrm{R}^{2}\right)$

\begin{tabular}{|c|c|c|c|c|}
\hline Model & R & R Square & Prediktor & Dependent \\
\hline 1 & 0,408 & 0,166 & KO, OCB, KT & KK \\
\hline
\end{tabular}

Sumber: Hasil perhitungan (Lampiran 6)

Tabel 7 menunjukan hasil perhitungan dengan menggunakan SPSS, didapatkan besarnya hubungan variabel bebas yang terdiri dari leadership transformasional, organizational citizenship behavior rdan komitmen organisasional dengan variabel terikat yaitu kinerja karyawan PT.Bank Rakyat Indonesia (Persero), Tbk Kantor CabangTulangBawang sebesar 0,166 atau sama dengan 16,60\%. Angka tersebut mempunyai arti bahwa sebesar 16,60\% variabilitas kinerja karyawan PT. Bank Rakyat Indonesia (Persero), Tbk Kantor Cabang Tulang Bawang yang terjadi dapat dijelaskan dengan menggunakan variabel leadership transformasional, organizational citizenship behavior dan komitmen organisasional terhadap turun naiknya kinerja karyawan Bank Rakyat Indonesia Kantor Cabang TulangBawang sebesar $16,60 \%$. Adapun sisanya yaitu $87,40 \%$ merupakan pengaruh variabel bebas lain yang dianggap tetap atau yang tidak diidentifikasi dalam penelitian ini.

\section{Uji Secara Keseluruhan}

Pengujian keberartian pengaruh variabel bebas secara keseluruhan terhadap variabel terikat digunakan $\mathrm{Uj} \mathrm{i}$ Fisher $(\mathrm{UjiF})$ dengan tingkat kepercayaan95\% atau $\alpha$ sebesar 0,05

Tabel 8. HasilUji secaraBersama-sama

\section{Anova $^{b}$}

\begin{tabular}{|c|c|c|c|c|c|c|}
\hline Model & & $\begin{array}{l}\text { Sumof } \\
\text { Squares }\end{array}$ & $\begin{array}{l}\text { D } \\
\text { f }\end{array}$ & $\begin{array}{l}\text { Meansquar } \\
\text { e }\end{array}$ & $\mathbf{F}$ & Sig. \\
\hline 1 & Regression & 3,170 & 3 & $\begin{array}{l}1,05 \\
7\end{array}$ & $\begin{array}{l}9,64 \\
2\end{array}$ & $\begin{array}{l}, 00 \\
0^{\mathbf{a}}\end{array}$ \\
\hline & $\begin{array}{l}\text { Residual } \\
\text { Total }\end{array}$ & $\begin{array}{l}15,892 \\
19,062\end{array}$ & $\begin{array}{l}14 \\
14\end{array}$ &, 11 & & \\
\hline
\end{tabular}

a.Predictors:(Constant),KO,OCB,KT 
Seminar Nasional Penelitian dan Pengabdian kepada Masyarakat Universitas Sang Bumi Ruwa Jurai Tahun 2020

b.Dependent Variabel:KK

Dari perhitungan SPSS dapat terlihat hasil uji statistic secara bersama-sama yang dapat dilihat diTabel8. Terlihat bahwa Fhitung sebesar 9,642 dengan nilai signifikansi sebesar 0,000, bila dibandingkan dengan Ftabel pada $n=149$ dan $k=3$ maka Ftabel sebesar 2,37. Karena Fhitung(9,642) Ftabel(2,37)selain itu nilai signifikan $0,000<0,05$ maka secara keseluruhan variabel bebas yang ada yaitu leadership transformasional, organizational citizenship behavior dan komitmen organisasional mempengaruhi variabel terikat yaitu kinerja karyawan PT. Bank Rakyat Indonesia (Persero), Tbk Kantor CabangTulang Bawang, dengan kata lain hipotesis yang menyatakan bahwa"terdapat pengaruh positif leadership transformasional, organizational citizenship behavior dan komitmen organisasional secara bersama-sama terhadap kinerja karyawan" didukung.Hasil ini menyimpulkan bahwa PT. Bank Rakyat Indonesia (Persero), Tbk Kantor Cabang Tulang Bawang merupakan organisasi yang sukses memiliki karyawan yang melampaui tanggung jawab pada pekerjaan formal dan bebas memberikan waktu dan energy mereka untuk berhasil dalam pekerjaan yang ditugaskan. Menurut Podsakoffet al. (2000), OCB mempengaruhi keefektifan organisasi. Adanya komitmen organisasional juga akan membuat pekerja memberikan yang terbaik kepada organisasi tempat dia bekerja. Pekerja dengan komitmen yang tinggi akan lebih berorientasi pada kerja. Pekerja yang memiliki komitmen organisasional tinggi akan cenderung senang membantu dan dapat bekerjasama(Luthan,2006:249). Agar perilaku OCB karyawan PT.Bank Rakyat Indonesia (Persero), TbkKantor Cabang Tulang Bawang ditunjukkan dengan baik, sangat diperlukan peran leadership transformasional dari pemimpin dan kepuasan kerja karyawan itu sendiri.

\section{Hasil Pengujian Hipotesis Secara Parsial}

Tabel 9. Pengujian Secara Parsial

\begin{tabular}{|c|c|c|c|c|}
\hline $\begin{array}{c}\text { Varia } \\
\text { bel }\end{array}$ & $\begin{array}{c}\text { Nil } \\
\text { ai } \\
\begin{array}{c}\text { Koefisi } \\
\text { en }\end{array} \\
\end{array}$ & $\begin{array}{c}\text { Nil } \\
\text { ai } \\
\text { Signifik } \\
\text { an }\end{array}$ & $\begin{array}{c}\text { t- } \\
\text { hitung }\end{array}$ & $\begin{array}{c}\text { U } \\
\text { ji } \\
\text { Hipote } \\
\text { sis }\end{array}$ \\
\hline Leadership & 0,202 & 0,012 & 2,541 & didukun \\
\hline $\begin{array}{c}\text { Organizational Citizenship } \\
\text { Behavior }\end{array}$ & 0,205 & 0,036 & 2,122 & didukun \\
\hline Komitmen organisasional & 0,099 & 0,092 & 1,695 & didukun \\
\hline
\end{tabular}

Sumber: Data Lampiran, Hasil output SPSS.

Berdasarkan data padaTabel 9 maka dapat dijelaskan hasil pengujian hipotesis sebagai berikut:

1) Pengaruh leadership transformasional terhadap Kinerja.

Nilai koefisien antara variabel leadership transformasional dengan variabel kinerja adalah sebesar 0,202 dengan probability sebesar 0,012 atau $p<0,05$. Ini berarti variabel leadership transformasional berpengaruh secara positif dan signifikan terhadap variabel kinerja karyawan PT. Bank Rakyat Indonesia (Persero), Tbk Kantor Cabang Tulang Bawang. Dengan demikian, hipotesis yang menyatakan bahwa leadership transformasional berpengaruh positif dan signifikan terhadap kinerja 
karyawan terbukti. Pemimpin transformasional merupakan penerapan visi diikuti oleh pentingnya penerapan pemimpin yang mampu membuat perubahan disemua aspek. Model leadership transformasional mampu menyediakan solusi dalam pemahaman tentang apa yang membuat seorang pemimpin memiliki pengaruh yang besar bagi pengikutnya atau karyawan sehingga dapat menciptakan peningkatan kinerja secara berkelanjutan.

Hasil yang berpengaruh mempunyai kesamaan hasil dengan penelelitian yang dilakukan Nawawi (2012) yang membuktikan bahwa leadership transformasional berpengaruh terhadap kinerja karyawan, pemimpin transformasional merupakan penerapan visi diikuti oleh pentingnya penerapan pemimpin yang mampu membuat perubahan disemua aspek. Model leadership transformasional mampu menyediakan solusi dalam pemahaman tentang apa yang membuat seorang pemimpin memiliki pengaruh yang besar bagi pengikutnya atau karyawan sehingga dapat menciptakan peningkatan kinerja secara berkelanjutan.

2) Pengaruh organizational citizenship behavior terhadap Kinerja. Nilai koefisien antara variabel organizational citizenship behavior dengan variabel kinerja adalah sebesar 0,205 dengan probability sebesar 0,036 atau $p<0,05$. Ini berarti variabel organizational citizenship behavior berpengaruh secara positif dan signifikan terhadap variabel kinerja karyawan PT.Bank Rakyat Indonesia (Persero), Tbk Kantor CabangTulang Bawang. Dengan demikian, hipotesis yang menyatakan bahwa organizational citizenship behavior berpengaruh positif dan signifikan terhadap kinerja karyawan terbukti. Dengan adanya perilaku OCB ini akan membuat kinerja karyawan semakin baik, karena perilaku ini membuat karyawan bersedia bekerja melebihi kewajibannya dan secara langsung akan membuat kinerja karyawan tersebut menjadi lebih baik.

Hasil ini berlawanan hasil dengan penelitian yang dilakukan Komalasari dkk (2009) yang membuktikan bahwa OCB tidak berpengaruh secara signifikan terhadap kinerja, tetapi mempunyai kesamaan hasil dengan penelitian Chiang dan Hsieh. (2012) yang memberikan bukti bahwa OCB berpengaruh terhadap kinerja karyawan. Penelitian ini mempunyai hasil bahwa OCB secara positif dan signifikan terhadap kinerja, yang dapat dijadikan asumsi bahwa OCB berpengaruh secara signifikan terhadap kinerja, maka dengan menggunakan dimensi, diantaranya adalah(1)Altruisme(perilaku membantu orang lain);(2) Conscientiousness(perilaku kehati-hatian, ketelitian atau perilaku melebihi prasyarat minimum); (3)Sportmanship(perilaku yang sportif atau kemampuan untuk bertoleransi tanpa mengeluh); (4) Civicvirtue (kebijaksanaan warga atau keterlibatan dalam fungsi-fungsi organisasi); dan(5) Courtesy (perilaku menjaga hubungan baik) yang kesemua dimensi OCB tersebut diasumsikan mempunyai pengaruh positif secara signifikan terhadap kinerja karyawan.

3) Pengaruh komitmen organisasional terhadap Kinerja.

Nilai koefisien antara variabel komitmen organisasional dengan variabel kinerja adalah sebesar 0,099 dengan probability sebesar 0,092 atau $p>0,05$. Ini berarti variabel komitmen organisasional tidak berpengaruh terhadap variabel kinerja karyawan PT. Bank RakyatIndonesia (Persero), Tbk Kantor CabangTulang Bawang. Dengan demikian, hipotesis yang menyatakan bahwa komitmen organisasional berpengaruh positif dan signifikan terhadap kinerja karyawan tidak didukung. Hasil yang tidak berpengaruh 
menyimpulkan bahwa semakin tinggi komitmen organisasi belum berdampak pada karyawan akan tetap tinggal dalam organisasi dan akan selalu meningkatkan kinerjanya.

Hasil yang membuktikan bahwa komitmen organisasional tidak berpengaruh terhadap variabel kinerja karyawan berlawanan hasil dengan penelitian Sulianti (2009), hasil yang tidak berpengaruh dimungkinkan bahwa pada indicator komitmen berkelanjutan,dan komitmen affective menunjukan bahwa responden sebagian besar memberikan pernyataan pada kategori sangat tinggi. Namun pada komitmen normative masih ada karyawan yang kurang setuju bahkan tidak setuju terhadap komitmen yang ada hal ini memberikan gambaran bahwa masih ada karyawan pada PT.Bank Rakyat Indonesia (Persero), Tbk Kantor Cabang Tulang Bawang yang masih berpikiran untuk meninggalkan organisasi yang ada saat ini dan mencari organisasi yang lebih baik, dan tidak mempermasalahkan pengorbanan pribadi yang sudah dikeluarkan untuk memajukan organisasi. Manajemen PT. Bank RakyatIndonesia (Persero),Tbk Kantor Cabang TulangBawang hendaknya menciptakan perasaan dan keterikatan yang kuat dalam organisasi, meningkatkan loyalitas merupakan cara dalam menjaga komitmen organisasional para karyawan. Tumbuhnya rasa komitmen setiap karyawan terhadap organisasi akan membawa karyawan terhadap keinginan dan keputusan untuk tetap berada dalam organisasi dan membantu memajukan organisasi melalui peningkatan kinerja dan mencapai visi dan misi organisasiyang akan dicapai.

Tingkat komitmen baik komitmen perusahaan terhadap karyawan, maupun antara karyawan terhadap perusahaan sangat diperlukan karena melalui komitmen-komitmen tersebut akan tercipta iklim kerja yang profesional. Individu yang terpuaskan dengan pekerjaannya cenderung untuk memenuhi komitmen terhadap organisasi, sehingga munculnya loyalitas pegawai terhadap organisasi, yang akhirnya menyebabkan pegawai tersebut memiliki rasa ketergantungan dan tanggung jawab pada organisasi.

\section{KESIMPULAN}

Penelitian ini merupakan studi yang bertujuan untuk mengetahui pengaruh leadership transformasional, organizational citizenship behaviordan komitmen organisasional terhadap kinerja. Populasi dalam penelitian ini adalah seluruh karyawan tetap dari perusahaan PT Bank Rakyat Indonesia (Persero) Kantor Cabang Pringsewu yang berjumlah 237 karyawan, besarnya sampel yang dapat mewakili populasi untuk diteliti adalah sebanyak 149 responden. Berdasarkan hasil pembahasan, maka dapat ditarik beberapa kesimpulan sebagai berikut:

1. Berdasarkan hasil penyebaran kuesioner dapat diketahui bahwa persepsi responden terhadap leadership transformasional berada pada kategori baik dengan mayoritas responden menjawab setuju atau mempunyai skor 4 terhadap pernyataan yang diajukan. Artinya, persepsi responden terhadap leadership transformasional berada pada kategori baik dengan rata-rata pada seluruh pernyataan responden mayoritas memberikan pernyataan setuju.

2. Persepsi responden terhadap variabel organizational citizenship behavior berada pada kategori baik, artinya persepsi responden terhadap OCB berada pada kategori baik, dengan modus pada seluruh pertanyaan responden menjawab 4 atau setuju.

3. Persepsi responden terhadap variabel komitmen organisasional berada pada kategori baik, meskipun ada 1 responden yang memberikan pernyataan sangat tidak setuju yaitu pada pernyataan 6 yang menyatakan berpindah keorganisasi lain sangat tidak etis, tetapi sebagian besar responden menjawab setuju terhadap pernyataan yang diajukan. 
4. Persepsi responden terhadap kinerja berada pada kategori baik, hasil kerja yang merupakan indicator kuantitas paling dominan dalam membentuk konstruk kinerja karyawan dan responden sebagai karyawan berusaha meningkatkan kesempurnaan setiap pekerjaan.

5. Berdasarkan hasil perhitungan secara bersama-sama variabel bebas yang ada yaitu leadership transformasional, organizational citizenship behavior dan komitmen organisasional mempengaruhi variabel terikat yaitu kinerja karyawan PT. Bank Rakyat Indonesia (Persero), Tbk Kantor Cabang Pringsewu, dengan kata lain hipotesis yang menyatakan bahwa" terdapat pengaruh positif leadership transformasional, organizational citizenship behavior dan komitmen organisasional secara bersama-sama terhadap kinerja karyawan" didukung.

Berdasarkan hasil perhitungan secara parsial hanya variabel komitmen organisasional yang tidak berpengaruh terhadap kinerja karyawan, sedangkan variabel leadership transformasional, dan organizational citizenship mempengaruhi secara positif dan signifikan terhadap kinerja karyawan.

\section{DAFTAR PUSTAKA}

Ardana, K., Mujiati, N.W., Sriathi, A.A.A. 2008. Perilaku Keorganisasian, Yogyakarta: Graha Ilmu.

Brahmasari, Ida Ayu dan Agus Suprayetno. (2009). "Pengaruh Motivasi Kerja, Kepemimpinan dan Budaya Organisasi terhadap Kepuasan Kerja Karyawan serta Dampaknya Pada Kinerja Perusahaan (Studi kasus Pada PT. Pei Hai International Wiratama Indonesia)." Jurnal Manajemen dan Kewirausahaan, Vol.10, No. 2, September 2008: 124-135. Universitas 17 Agustus Surabaya.

Chiang, C.F., and Hsieh, T.S. 2012. The impacts of perceived organizational support and psychological empowerment on job performance: The mediating effects of organizational citizenship behavior, International Journal of Hospitality Management, Vol 31, pp. 180 190.

Dunn, M.W., Dastoor, B. and Sims, R.L. 2012. Transformational Leadership and Organizational Commitment: A Cross-Cultural Perspective, Journal of Multidisciplinary Research, Vol 4, No 1, pp. 45-59.

Gibson, J.L., Ivancevich, J.M., Donnelly Jr. 2009. Organisasi: Perilaku, Struktur, Proses, Edisi Bahasa Indonesia, Tangerang: Binarupa Aksara.

Luthans, F. 2006. Perilaku Organisasi, Edisi Sepuluh, Yogyakarta: Penerbit Andi. Mannheim, B., and Halamish, H. 2008. Transformational Leadership As Related To Team Outcomes and Contextual Moderation, Leadership \& Organization Development Journal, Vol 29, No 7, pp. 617-630. 